\title{
Residential Aged Care Facilities \\ Places for Living and Dying
}

\section{DEBORAH PARKER}

UNIVERSITY OF QUEENSLAND

\section{-INTRODUCTION}

In modern Western societies such as Australia there is an emerging pattern of population ageing. In 1901 people sixty-five years and over comprised four per cent of the total Australian population, by 2002 this had risen to thirteen per cent and by 2051 it is predicted to reach twenty-four per cent with those over the age of eighty growing the fastest of any age cohort. ${ }^{1}$ For approximately seven per cent of those who are aged sixty-five and over the final months or years are spent in residential aged care facilities (RACFs). ${ }^{2}$ In 2007, eighty-eight per cent of permanent separations from RACFs in Australia were from the death of the resident. Of those residents who die in these settings, seventeen per cent have a length of stay less than three months and nineteen per cent less than twelve months. ${ }^{3}$ From these figures it is clear that RACFs are spaces and places where dying and death occur. Despite this, limited attention has been given to how death is experienced in this setting and how the setting itself impacts upon this experience. ${ }^{4}$ 
The terms space and place are often used in geographical gerontology, sometimes interchangeably. Wiles notes that space is a more universal and abstract idea whereas place is more specific, a portion of space, a setting which is experienced and which holds meaning, and which shapes the intimate relations between people. ${ }^{5}$ Gilmour notes that space, both material and imagined, is produced through action and interaction whereas place is the organisation of space into bounded settings where social relationship and identity take place. 6 Here, I explore RACFs as both spaces and places of death and dying. I use the term 'place' as the setting of care; in this instance the RACF is a hybrid place where both living and dying occurs. Space refers to different areas within the RACF where the living and dying intersect. These spaces, far from being fluid, are rigidly defined not by those who live there but by those who define the space as a 'working' space. Together, space and place constitute the scenes of death I explore in this essay.

While institutions play a key role in the care of the dying, there is evidence that within institutions dying patients are sequestered and care is less than optimal. In many cases, this involves an effort to 'screen off' the death scene, to marginalise it within the institution. Sudnow's classic ethnography of death and dying in two American hospitals, conducted in the 1960s, illustrated how work patterns of nursing staff hid the reality of patient's dying. ${ }^{7}$ He cites examples of patients admitted to the emergency department at night who were expected to die but were not assigned a bed. Rather, they were placed in the supply room until morning. If death had not occurred overnight, a bed was assigned before visitors or medical staff came in. Glaser and Strauss, who studied hospital care in the 1960s, similarly identified a death denial culture in hospitals. They found that dying patients were placed in side rooms, were assigned a room with a comatose patient or, if in a multibed room, were permanently screened off from other patients. ${ }^{8}$

Other more recent examples of sequestration of dying in hospices and hospitals has been documented by Lawton and Golander. ${ }^{9}$ In Lawton's ethnographic study in the United Kingdom during the 1990s, the hospice presented a paradox. On the one hand, hospice promotes openness of death and communal dying, with many patients cared for and dying in four-bed rooms. On the other hand, Lawton noted certain types of patients in the hospice were sequestrated into single rooms. These she classified as having 'unbounded bodies'. That is, a patient for whom there was a 
breakdown of the physical body boundary which involved fluid or matter that would normally be contained leaking to the outside. ${ }^{10}$ Golander's ethnographic study of a geriatric nursing ward in Israel found that once a resident's health deteriorated, a transfer was made to a six-bed intensive nursing room in a different building from the nursing ward. Once the dying resident had been transferred they were not visited by residents from the nursing ward.11

In residential aged care, sequestration of the dying has been reported by Gubrium, Hockey and Froggatt. ${ }^{12}$ In Gubrium's study of a nursing home in the United States during the 1970s, residents were assigned space according to their physical deterioration or the perceived closeness to death of the resident. The fitter residents occupied the lower floors and the frailer patients (those expected to die) were on the upper levels. Those residents on the lower floors did not venture upstairs and were uncomfortable with the frailer patients infiltrating their space. The assumption made by the residents and staff was that only the frail residents on the upper floors would die. When an unexpected death occurred on the lower floor this disturbed the residents by bringing death into the living space. ${ }^{13}$

In her ethnography of a residential care home in the United Kingdom, Hockey found that residents were considered either 'fit' or 'frail' and space within the home allocated accordingly. This time the frail occupied the lower floor of the institution with the upper floor available only to the fit. This distinction of space minimised the exposure that the fit would have to scenes of death and dying, but as in Gubrium's study death could occur anywhere in the home. ${ }^{14}$ Froggatt proposed that for residents of nursing homes who are more physically dependent than those in the residential home studied by Hockey, the boundaries between life and death may not be as clearly defined. Rather, transitional states are created, which residents could occupy either temporarily or permanently. Residents could be classified as generally deteriorating, with increased physical, mental and social care required. However some residents were noted to have 'bounced back' from the brink of death. One category that staff used to identify residents who were in a transitional state was 'being poorly'. This category portrayed to staff and relatives that the person's condition had changed, and that they might die. Residents in this category were separated from other residents as care needs increased and staff made the decision they should be excluded from social activities. As a consequence, 
more time was spent in their bedroom and less in public spaces such as dining and lounge areas. ${ }^{15}$ In Australia, there are no ethnographic studies such as these to illustrate the use of spatial separation of death and dying. I aim to identify how the use of space within residential aged care impacts on residents' self-identity, and on the nature of death scenes within RACFs.

\section{-Methodology}

This essay is based on an ethnographic study conducted during 2001 and 2002 of two residential aged care facilities in Adelaide, Australia. I spent a total of 188.5 hours as a participant observer, seventy-two hours in the first facility over a fourmonth period and 116.5 hours in a second facility over a five-month period. During this time, extensive field notes of the observations of the interaction for eleven residents, their family and staff provided rich descriptions of the complexity of social as well as nursing and medical interactions that occurred prior to and at the time of death. In addition, documents such as the resident's case notes were reviewed; these gave textual information on the care provided to the resident and their family. Of the eleven residents, six died during the study period with all but one of these deaths occurring in the facility. As I discuss space and place, the physical layout of each facility is important and is briefly described below.

\section{Facility one}

The first facility had thirty-two high care beds in a secure unit at ground level. On the same site were low care beds and independent units; however, the participant observations were focused on the thirty-two-bed secure unit. There was a mix of single and twin rooms, with entrance to the double rooms at one end. This meant that staff must pass by the first resident's bed to attend the resident in the bed furthest from the door. Privacy between the two bed areas was provided by a material curtain on roof tracks. There were four communal areas-two lounges, the first a large open area was used for activities and special events; the other a smaller room designed for individual visitors. This had a door for privacy and to reduce the noise from the corridor. The remaining two spaces were dining areas, one specifically designated for residents with dementia who required assistance with meals and the second for residents who required no or minimal assistance. 


\section{Facility two}

The second facility had thirty-four high care beds in two linked wings and ten beds in single en-suite rooms in an area known as the frail hostel area. The frail hostel residents were, for funding purposes, classified as high care. Under the 'ageing in place' philosophy, however, they were not moved to the high care area. ${ }^{16}$ On the same site were other low care beds and independent units. My participant observations were focused on the thirty-four bed high care beds and the ten frail hostel beds. Most rooms of the thirty-four high care rooms were single with the exception of four twin-share rooms. There were two communal areas in the high care area which served the dual purpose of lounge and dining rooms. Between the high care and frail hostel beds was a large dining room predominantly used by the frail hostel residents and other low care residents. Only high care residents who were independent with meals were allowed to eat in this dining room.

\section{-SPACES OF LIVING AND DYING}

A residential aged care facility holds different meaning for those that work, live or visit them. For older people who live there they are home and should afford privacy and safety. They are also places where social care is provided alongside nursing and medical care. It is the duality of these care needs that sets RACFs aside as different from other health care settings such as hospitals or hospices. In contrast to residential care, the focus in hospitals is on diagnosis, treatment and discharge. While traditionally hospices were focused on social as well as nursing and medical care, today they have become assessment and treatment centres where length of stay is often reduced to weeks or days. RACFs need to be functional, safe and efficient, but constraints exist on staff use of space to ensure spaces are as similar as possible to a home-like environment for the resident. Family members, like the residents, are looking for a combination of social and clinical care within a home-like environment.

RACFs operate as both places of living and dying. The mission statements or philosophies of the two RACFs were examined to ascertain whether they reflected this duality. The vision and mission statement from facility one focused on the importance of providing quality services to support older residents. Statements identified the need to respect the privacy and dignity of individuals, self-reliance, 
fostering of family relationships, promotion of safety, quality of life and integrity. Although there was no specific statement regarding palliative care, the value statements reflect the philosophy of caring for dying residents. Facility two had a philosophy document. which similarly acknowledged the dignity of the individual, enhancement of wellbeing and the promotion of independence. This statement also acknowledged the importance of providing supportive care when required. There was no specific reference in either facility's statements that RACFs are places that care for the dying, a lack also found by O'Connor in her discourse analysis of aged and palliative care documents in Australia. ${ }^{17}$

Despite mission statements not reflecting a focus on caring for the dying, the actual care practices did show that dying and death were seen as important within the two facilities. This was apparent in the education and commitment by staff to provide appropriate care to dying residents and bereavement care to the families. Staff also recognised when a resident was dying and made use of advance directives and care planning to ensure the resident's and family's wishes were followed. Other factors included formal links to specialist palliative care services, care at the time of death, and the acknowledgement and celebration of the individual life within the facility.

How the care of the dying is managed in RACFs is related to physical and spatial layout, with furniture arrangements, lighting or environmental props used to communicate a particular narrative. Many RACFs strive to create a home-like atmosphere, a 'sense of place', by incorporating design features that resemble an individual's home. Nonetheless, they are also places where people die. As such, spaces within RACF need to be created that are suitable for these dual functions of living and dying.

Space within each facility was designated by the staff and based on resident function. Those who were cognitively intact or physically able to feed themselves were placed in one section of the dining areas; those with dementia who had wandering behaviour, or those whose cognitive or physical incapacity meant they were unable to feed themselves, were housed in another section. This was most pronounced in the second facility, where only high care residents who were able to eat independently and not be an embarrassment to other residents could use the dining room. Once these residents reached a level of dependency or frailty where 
this was not possible, they were removed from the dining room list and their meals were served in the dual purpose lounge/dining areas. For those approaching death, meals were served in their rooms if they were still eating.

This spatial segregation was reflected in other communal spaces including lounges, where physical placement of residents was based on their physical and cognitive function. On most occasions, residents taken to the communal dining and lounge areas could be in these spaces for hours at a time. These residents were unable to relocate themselves because of either physical limitations or cognitive incapacity. There seemed no attempt to maximise interaction between residents, despite the daily routine of having all residents bathed, dressed and ready for the communal areas by mid morning. Once there, apart from the occasional activity, there was no social interaction.

There were, however, two groups of residents who were exempt from spending time in the communal areas. The first were residents who refused to use the communal areas. These residents had an elevated status within the RACFs and their requests were respected by the staff. These were residents who had no cognitive deficit and were able to negotiate their own routine. The second were the residents considered to be dying. Residents considered dying had permission to suspend the expectations of communal participation. There appeared to be an assumption, made by the staff, that the dying person would prefer not to participate in activities or spend time in communal spaces. This was not usually negotiated with the individual resident or their family but rather assumed by staff members.

In some instances the living spaces in the high care area become temporary dying spaces. This was most common in the first facility, where residents from low care might be accommodated when no bed was available in the high care area. This would only happen if it was thought that death would occur relatively quickly; to avoid transfer to the acute hospital, the resident and family were accommodated in one of the communal spaces that could be closed off to other residents. This option was open for only a few days and was at the discretion of the staff. In a conversation one morning with the care director from the first facility, I was told a low care resident was temporarily occupying the small lounge room near the entrance. The care director reported that other residents who were more cognitively aware accepted that the room was used in this way. I had no comments from residents 
indicating they were comfortable with this space moving from a living to a temporary dying space. This may indicate that generally the room was not highly used by residents as most had single rooms where family visits were conducted.

-DISCOURSES OF LIVING AND DYING

The experience of individuals within defined places such as RACFs is not only shaped by the spaces and how they are designated and occupied but also through language. An observational study of conversations held in RACFs between nursing staff and residents on a morning shift found an over-emphasis on health or sickness topics after the morning greetings. ${ }^{18}$ As it is the staff who guide the focus of the conversations, this leads to a major focus of conversation on the body, and in particular the physical limitations, of the resident. In effect this makes the act of communication instrumental in determining the person's function. My observations in both facilities identified that verbal interactions between staff and residents were predominantly focused around the physical tasks being provided. Depending on their designation, the staff had different interactions with the residents and families. The registered nurse's (RN) time is often spent doing medications, whereas the care workers are responsible for more personal care. Interactions occur during the routine tasks of bathing, turning or assisting with toileting. My observations were that the domestic and kitchen staff often developed good relationships with the residents, particularly those who had been in the facilities for a long time. This was more evident after a resident had died and staff were debriefing or discussing attendance at the funeral.

While talk was predominantly biomedical and focused on physical tasks, there was also death talk and often this included phrases such as 'for comfort care', 'for palliation', 'for palliative care', 'deteriorated' or 'change in condition'. To refer to residents who died, staff used euphemisms such as 'passed away' or 'gone to God'.

Elizabeth was one of the residents who died during the study. She was very open about talking about death and dying, her own and that of other residents. When other residents whom she knew had died, she would tell me a bit about them, and if they had family. In one of our conversations she said:

'I'm getting close now' (referring to her own death). She said the Dr was trying to keep her going but she was determined to die with a smile on her face, she hoped 
that she would win. She said she was planning to die in her bed here she had signed the forms that indicated she did not want to go to hospital or be moved into the nursing home section. I asked if that was a difficult decision. No 'you live and die. It's a fact of life. I've had a good life, you never dream when you're your age (mine) that you come up to a place like this you just get on with what you need to do. It's the same now you do what you need to do.' (Field notes-Facility two).

Interactions between residents were often limited by their hearing deficits or cognitive abilities. Those interactions that did occur were often between persons who received the same level of care, as it was otherwise hard for residents to find common ground. Elizabeth indicated that it was hard to maintain conversations with residents who are in the different levels of care, because they talk about things that don't concern her any more. While she was in one of the more independent sections of the facility her frailty had precluded her from engaging in outside activities that the other residents had as part of their social interactions:

'I am getting to know the other ladies at the lunch table' but they have conversations that don't concern her. She explained they were 'independents' (her language) and I am high care (her language). They talk about the price of tomatoes and other shopping or outside business. I've been there and done that. It doesn't interest me any more. I pretend that I don't hear them and then I don't have to try and join in these things that don't concern me any more.' (Field notes-Facility two).

Certain symbols within the two facilities communicated particular narratives of death and dying. In both facilities there were three symbols that appeared as a resident became regarded as terminally ill; that is, days or weeks from an expected time of death. These were an electric aromatherapy burner, a CD player and a plastic kidney dish with mouth cleaning supplies. In addition, depending on the resident's symptoms, an additional fourth symbol was the introduction of a Graseby pump (an automated syringe driver) for pain control.

These symbols instigated by senior nursing staff appeared to signify to staff of all levels that this person was expected to die, probably within days. Inadvertently, it also signalled to the family an increase in vigilance was required as death might be imminent. Should death not occur and a resident return from the brink of death, these symbols were withdrawn - to be reinstated if death again appeared imminent. The choice of these objects to symbolise impending death 
appears to have originated from the palliative care movement. A feature of educational training in specialist palliative care service, which many staff undertook, was the use of aromatherapy or massage, music and recognising the importance of maintaining a moist mouth as residents became unable to tolerate food and drink. Graseby pumps for pain relief, when a resident is unable to manage oral medications, are also advocated by specialist palliative care services. Training in the use of these pumps is routinely included in educational sessions.

Colin, who died in the second facility, had aromatherapy, massage and music therapy initiated a month before his death. My field notes the following day reflect the continued use of symbols associated with terminal care:

I went into Colin's room he looked grey and did not respond when I entered the room. I walked closer to the bed and he did not stir. He was turned toward the door with the blankets up over him, just his head showing. He looked a little unshaven, I noticed in his room was an electric aromatherapy burner; there was a faint citrus smell. A CD player was playing classical music. Also in the room was a mouth tray. (Field note-Facility two).

Text as well as talk can influence the way narratives of the dying are assembled and formed with particular themes, subjectivities and story lines. Texts of identity can be used to formulate who we are. These may be documents such as personal or professional files and in the context of RACFs available text included the resident's medical and nursing case notes, care plans and other correspondence. The selves constructed in texts can perpetuate a person's presence even after they are absent from the setting. Woven together, texts can be organised into chains of self construction and contents interpreted into narrative resources for whomever's business it is to eventually assemble and represent their subjects' identities.

A common example in RACFs is when nursing staff assess and document the resident's physical, social, psychological and spiritual needs primarily in relation to the level of reimbursement to be claimed. The use of language that is acceptable within the institution is different from that external to the setting. An example occurred where one resident, Henry, had documented in his notes that he reported to the morning staff that he had had severe chest pain during the night. As the night staff had failed to document the incident, the staff member did not believe the resident. She documented in his notes: 
Resident told me this morning (0900) that last night he had severe chest pain and that the staff had to give him oxygen. Nothing to this effect documented and he is well, so presumably he was delusional. (Case notes-Henry).

But what Henry had told the staff was factual, and it wasn't until the night staff member returned and saw this documentation that she corrected the entry.

The importance of documentation and its relationship to funding is reflected in the effort that is expended by staff to ensure every activity related to a resident's care is recorded. Each resident has two documents: an extensive care plan, usually kept in the resident's room (although not on display), and the resident case file, in which all other information related to personal, financial and health care needs are catalogued in sections. Through this documentation, staff complete a resident classification scale (RCS) which was the funding instrument used by the Commonwealth Government at the time of the study. Completing the RCS required elaborate documentation, but this was related primarily to the physiological status of the resident, with functional capacity recorded in deficit terms rather than accomplishment of competence. It is a very time-consuming activity and one taken very seriously. The threat of losing money from poor documentation is always a concern of the care director, as I observed in one facility:

The Care Director explained Fridays is RCS day. She and an RN get together and work through the residents whose RCS is due the following month. They check the care plans and assessments, see if any interventions are needed to be put in place. They work a month ahead so that they have time to make sure everything that is needed to make the assessment is in place. They have a list of all residents which is colour coded to which month their assessment is due. It seemed that at any one time there were 5 or 6 residents that this applied to. 'It's a very negative way of getting funding for peoples care. You have to make them look like deviants and it stereotypes older people, if they have a problem you capitalise on it so you can claim more money so ultimately they can get the care they deserve'. (Field notes-Facility one).

As a resident's condition deteriorated, the case notes reflected this, although predominantly from a biomedical perspective. There was usually reference to palliative care plans or advance directives that were in place or discussions with family regarding the resident's physical condition. Documentation of a resident's death was usually factual. After Joyce's death in the first facility, for example, the GP 
made detailed comments and identified the cause of death, while the nursing staff documented family concerns:

MEDICAL NOTE-Patients death confirmed. Pupils fixed, dilated. Heart sounds $O$, respiration absent. Cause of death-pneumonia. Associated co-morbiditiesHypertensive heart disease, aortic stenosis, thrombocytopenia, macular degeneration, deafness, hiatus hernia, reflux, and fracture left humerus.

NURSING NOTE_Family present at time. Funeral Director will collect body at 1930. One gold ring left on finger and receipt for this was left by Funeral Director to say they had the ring. (Case notes-Joyce).

\section{—SCRIPTS OF LIVING AND DYING}

James Holstein and Jaber Gubrium argue that the self is narratively constructed, influenced by a sense of what we should be at particular times and places but tamed by the social arrangements in which selves are produced. ${ }^{19}$ They argue that the personal self is influenced by social interaction but has a private location that is a space for personal experience. But social interactions may intrude on this personal self and erode it. For individuals who reside in institutions such as RACFs there is a danger that this personal self can be decentred and this can lead to a deprivatisation of the inner self. This is most evident in 'organisational settings, where the personal self is discerned in public space and produced in social interaction'. ${ }^{20}$ By viewing the social self in this way it allows for multiple self constructions rather than an ideal integrated self. This provides corroboration for Holstein and Gubrium's view that lives are conducted within a variety of social institutions, each with their own way of operating. It is these institutions that shape the multiple self constructions that allow individuals to operate. ${ }^{21}$

This section of the essay explores how the self is constructed in RACFs, by exploring the scripts of self identity that are available within the setting. Seale argues that scripts help individuals to make sense of events, relationships, and their sense of self. ${ }^{22}$ Individuals who wish to understand how to die well can draw on a number of such scripts to organise their coherent personal story. In this study four scripts appeared to influence the construction of self for residents. These scripts are based on interactions that occurred between residents, their families and staff. They 
are the economic self, the embodied self, the dying self and the other constructed self. Each will be briefly discussed drawing on individual residents' narratives.

While each of the facilities incorporated the discourse of dying, they were constrained by the current economic conditions affecting aged care in Australia. The need for RACFs to meet legislative standards and to secure ongoing financial reimbursement gave economic and biomedical discourses a priority as a focus for the organisation of work. The direct linking of resident care needs and dependency measures to a dollar figure is illustrated by documentation focused on economic and biomedical factors with little attention to individual social and personal circumstances. Residents' identities are constructed via documents and institutional talk within an economic discourse, in essence producing the economic self.

The documentation supporting the construction of the economic self was either that of the actual care required by the resident or support perceived as needed by the family. Documentation of the person captures and fixes the person as a 'file-person' constructed by a 'file-master' or 'file masters' ${ }^{23}$ Each resident had a case file, which was kept in the nurse's station. A care plan was usually kept in the locker or wardrobe in the resident's room. Care plans were mandatory but were long documents. During the time I spent in the facilities, I did not see staff use them to guide the residents' care, other than to complete charts located in the care plan folder. Considerable time was spent in making sure these were completed to meet the requirements for the RCS and any accreditation visits.

Care workers, in particular, found the required documentation timeconsuming and bearing little relation to the care they provided. Documentation is required to support any claims made for economic reimbursement using the RCS. Behavioural problems are one area that can be used to maximise points:

The Care Director was in the office talking to a care worker about her notes for the day. The care worker had written something like Mr X, happy and comfortable today. The Care Director said to the care worker 'we can't claim money for behavioural problems if it's not documented. What you need to write is that because you did certain things like talked with the resident, joked with him, sat with him etc then he was settled and had a good day'. (Field notes-Facility one).

Where care practices and social interactions focus on the physical limitations of the person's body the person can be reduced to an object of care. 
Gubrium used the term 'bed and body work' to describe physical care tasks required for residents. ${ }^{24}$ This bed and body work forms the core tasks carried out by nursing and personal care staff. Completing the bed and body work required in the time allowed, given the staffing mix and financial allocation provided, results in what Tuckett refers to as instrumental rather than affective care; care based on tasks rather than offering emotional support. In a culture that supports instrumental care, individual needs of residents are secondary; they must fit into the ward routine. ${ }^{25}$ Social interactions that occur between residents and staff aim at completing the bed and body work required. Bed and body work provides a script for identity construction which I refer to as the embodied self. Caring for a body, as opposed to a person, means staff orient their interpersonal communications differently. Care requires physical, but not social and psychological, investment.

The diminished capacity of a resident's physical function highlights the resident's embodiment and has an impact on their sense of identity. Elizabeth uses a walker in order to be independently mobile for short distances. She has assigned a name to her walker and has embraced this as an extension of herself. At one point the physiotherapist arranged for a replacement walker but Elizabeth quickly dispensed with this new one, indicating that it did not fit as comfortably as her old faithful. Elizabeth also recognised her failing body, which sometimes spilled food at meals. Rather than be embarrassed, she embraced this aspect of her embodied self and employed a bib similar to those used in the high care area by residents unable to feed themselves. In her case it was stylish and personalised. Elizabeth wore it not as a mark of deterioration, but as an item of clothing:

When we arrive in the dining room Elizabeth puts her walker against the wall and shows me her table. It is the first one from the corridor so she does not have to negotiate her way through the tables. Out of her wheelie walker basket she takes her purse from a small laminated shopping bag with 'Harrods' written on it. Also she has a mauve soft cloth with a wire necktie and clip. She says 'this is my bib. I sometimes spill my food because my hands shake so they gave me this'. At this point, Elizabeth's sister who lives in an independent unit arrives and sits at the table next to Elizabeth. Elizabeth is explaining to me that people who use this dining room (low care) are a mix of high care and low care (Elizabeth's choice of words). Elizabeth's sister 
comments that she is a no care meaning in the independent units. (Elizabeth-Facility two).

Elizabeth is aware that to maintain her privileged space within the low care dining room, which is also used by residents from the independent units, she must maintain a certain level of physical and social function. In the evenings, when she is tired, she eats in her bedroom. In this way she monitors the amount of energy to portray the embodied self that will allow her to remain in the low care area, and not precipitate a move to the high care area.

For people who are dying, maintenance of identity is affected by the physical effects of disease on the body and by institutional practices. Earlier, this article highlighted how both the RACFs studied demonstrated institutional practices that acknowledged the care of dying residents and their families, including bereavement support. As a consequence, one script available for the construction of identity was that of the dying self, though not all residents who die have a dying identity. The dying self was assigned by the staff and sometimes by the family but not usually by the resident themselves; it referred to the last few days or weeks of life. For those whose death is sudden, without a period of deterioration, the move from the category of living to dead bypasses the script of the dying. Similarly, not all residents constructed as dying continued on a downward trajectory to death.

Documents in Joyce's file reflected the rapid trajectory of her embodied and dying self. Documentation focused on her physical comfort, evidence of impending death and the bed and body work attended to by staff.

DAY OF RETURN FROM HOSPITAL

Resident returned to nursing homes 1030. Commenced regular analgesia. Discussion with family and manager-bed rails up, form signed.

1740 Medical review-Morphine 5mg sc stat and 4/24. Maxalon 5mg sc stat and 8/24 if needed.

2130 Dr contacted due to resident having vomit X 3. Wrote up previous orders.

DAY FOUR AFTER RETURNING FROM HOSPITAL

Am report Morphine $5 \mathrm{mg}$ and Maxalon given 0755 with good effect. Resident slept soundly. Accepted breakfast then vomited. Suppository moderate result.

Pm Report-Morphine 5mg and Maxalon 5mg given 2225. C/o restlessness. Repositioned, rehydrated, resting well. Ate good meal with family assistance. 
Night duty 0640-Remained comfortable. Resident condition poorly. Some episodes of Cheyne Stokes @0630.

MEDICAL NOTE-Significant deterioration. She has become dehydrated because of vomiting and weakness despite the use of Maxalon-although Maxalon has significantly reduced the vomiting. She is now febrile ( $T$ 38) with signs of $R$ sided pneumonia. Comatose at present. Pupils equal and small. Her condition is terminal. Relatives are satisfied with the present management and understand that her condition is terminal.

Pm report 1415-Morphine 5mg s/c given at 0750 for comfort care. Daughter notified earlier this shift of resident's deterioration. Various family members in attendance all shift. Further $5 \mathrm{mg}$ morphine given at 1350. All care attended to.

18/8/01-Medical note 1750-patients' death confirmed. Pupils fixed, dilated. Heart sounds 0 Respiration absent. (Case notes-Joyce).

This factual construction clearly located Joyce within a dying discourse, but it focused on the technical aspects of care. Missing was the social and psychosocial discourse of dying. This included the family's vigil at the bedside, an intricate roster to ensure at least one family member was present for those last few days. The family's loving attempts at providing comfort by offering sips of water, stroking her head, and massaging her hands and feet were not reported, nor were interactions with the resident in the same room, who had opted not to be moved. There was also an absence of any documentation of conversations between the care director and the family regarding Joyce's poor prognosis and daily worsening condition. The use of the word 'terminal' did not appear until the day of death.

Individuals have physical and cognitive resources that they can call upon for the preservation of their identity. Identity constructed prior to their entry to the facility may have drawn on their status in the community, previous occupation and family connections as well as physical and mental capacities. For some residents, new identities may have been constructed by entering the facility; this might be particularly the case for married residents who lose the status of husband or wife once in the home. For some residents who no longer have the cognitive capacity to maintain or construct their identities, family may construct the identity of the person as it was before. A script available for construction of identity was the other constructed self. Construction and maintenance by the family of an individual's self 
identity, for individuals that are not cognitively able, helps the family persist with the current relationship despite no recognition or social engagement occurring. Doing so means that individuals with cognitive impairment (such as dementia) who engage in untoward behaviour such as abusive or inappropriate language retain elements of their social or personal identity, constructed from the past by others.

A consequence for the family of the person's loss of identity is that interactions may need to be structured in a different way. This may be that the parental relationship in interaction with children is lost, or spouses may lose the husband or wife role and become like a daughter or son. The preservation strategies employed by family can serve to manage the other's presentation of self, without the purposeful participation of the cognitively impaired individual self.26

Sudnow defined social death as referring to the point at which 'socially relevant attributes of the patient begin permanently to cease to be operative as conditions for treating him, and when he is essentially regarded as already dead'. ${ }^{27}$ For Kalish, social death can be self-perceived, with individuals thinking they are as good as dead or that others perceive them as as good as dead. ${ }^{28}$ It is, however, possible to be socially dead in one person's view but not in another's. Some family members may view their relative as socially dead and have no personal contact, whereas another family member may maintain contact on a regular basis. Wilma was a resident unable to verbalise, but her daughter did not consider her socially dead despite years of limited conversation and sometimes abusive behaviour. Wilma's daughter interacted with her mother as socially alive, visiting her twice daily and being very particular about how her mother was dressed. She asserted the importance of maintaining her mother's self identity:

Wilma's daughter was insistent that the staff dressed her mother in matching colours and that she had proper stockings and shoes on despite that she had not been weight bearing for years. The staff were very aware of this request and each time I saw Wilma she was dressed as her daughter instructed. In each of the facilities there was a hairdresser on site and Wilma like most of the female residents attended regularly. This was despite the fact that as she was either in bed or a chair with a high back it was difficult to maintain a decent hair style. (Field notes-Facility one).

To maintain her mother's identity, Wilma's daughter had a diary in which visits by family could be recorded. The daughter and other family members wrote 
what Wilma was like physically, cognitively and emotionally at each visit. She had also requested that each person who visited wrote in the diary so that Wilma could be reminded who had visited and what they had said. This was a strategy to reduce the social death of Wilma.

Wilma's daughter described to me the importance of maintaining her mother's identity and the use of the diary to aid this as well as a record of her commitment to her mother. She sometimes flipped back through it and it provided a reminder of the progressive deterioration of her mother and how she felt at times. It also reminded her of the times when her mother was able to communicate and of the conversations or jokes they had shared. This helped her to maintain a sense of who her mother was as she became increasingly less recognisable. This acceptance over time by the daughter of her mother's condition had led the daughter to indicate she was prepared for her mother's death.

In contrast, Daisy's husband, who was very attentive, was less insistent on maintaining the identity of his wife through clothes or a diary. Daisy had severe dementia and had been admitted to the facility originally for terminal care, but this was some months previously and her condition had not dramatically changed. My conversations with her husband revealed that he had chosen to stop his daily visits and instead become more involved in the activities of the retirement village where they had both lived. While he still loved his wife he acknowledged that she probably did not recognise him. This detachment was demonstrated on their wedding anniversary which he had chosen not to formally celebrate, as he was not sure his wife would be aware of the significance:

'I signed the forms to say no more treatment but on she goes. I believe in euthanasia in these instances. She has no quality of life; I come down most days in the morning but don't stay for long you don't get much back. I'm presuming she knows who I am but I couldn't be sure. It's our 60 th wedding anniversary today'. (Field noteFacility two).

Daisy's husband loved his wife, but my perception was that she had become socially dead although biologically alive. The effort required for her husband to maintain her identity as his wife had become too difficult.

These four possible scripts of self construction are proposed as providing resources for the residents in this study to construct identity. The scripts are 
generated from the discursive environment described earlier, and are needed for the institutions to function. Thus the economic self reflects the economic discourse pervasive through talk and documentation within the two facilities. Similarly, the embodied self is created to serve the economic and biomedical discourses. Economic, as the body that requires attention is worth money, and biomedical, as residents' daily routines are situated around the bed and body work of the institution.

While the economic and biomedical scripts for identity construction can be applied to all residents within the facilities, the dying script may not. Qualification for the dying script can be constructed by the resident themselves, family members or staff. Residents may enter or exit from the dying script, and adjustments in social interactions between residents, families and staff are made. The final other constructed script can be universally applied to residents, as through social interaction individuals will always construct the other in some way. The main discussion for this script applies to those residents who for cognitive reasons have more difficulty conveying their own identity. Family members can construct the resident's former identity through maintaining physical appearance and through their own attention to the social functioning and personal identity of the person.

\section{-CONCLUSION}

Many Australians will experience their own death scene in a RACF. RACFs need to be understood as places incorporating a variety of spaces of death. These places and spaces frame who and what we are at particularly vulnerable moments in our lives. These institutions mediate, but also sometimes efface, carefully constructed personal identities. In doing so, they shape end of life experiences in complex, sometimes subtle, often invasive, but always intimate, ways. Inhabitants of RACFs use a variety of codes and materials to forge the selves they must demonstrate to get on with living and dying under these institutional circumstances.

Understanding the complexity of these settings is required to improve care of people dying in RACFs. Taking the construction of identity as the focal point demonstrates the importance of understanding how institutions limit who and what the residents can be. While RACFs are increasingly incorporating discourses of dying, these compete with dominant economic and biomedical discourses. It is important, therefore, that RACFs be seen as places incorporating a variety of spaces 
where living and dying coexist. In this way, RACFs may become more conducive places for a variety of personal and interpersonal scripts to emerge, as individuals, family, friends and staff enact and experience the intimate spaces of the death scene.

Associate Professor Deborah Parker is the Director of the University of Queensland/Blue Care Research and Practice Development Centre (RPDC) and Director of the Australian Centre for Evidence Based Community Care (ACEBCC). She is a national and international expert in palliative care for older people.

\footnotetext{
-NOTES

${ }^{1}$ Commonwealth of Australia, Australian Social Trends 2004, Australian Bureau of Statistics, Canberra, 2004; J. Stevens, J. McFarlane and K. Stirling, 'Ageing and Dying', in Allan Kellehear (ed.), Death and Dying in Australia, Oxford University Press, Melbourne, 2000, pp. 173-89.

2 D. Parker and A. McLeod, 'Assessment of Need in Care Homes', in Jo Hockey and David Clark (eds), Palliative Care for Older People in Care Home, Open University Press, Buckingham, 2002, pp. 34-51. ${ }^{3}$ Australian Institute of Health and Welfare, Residential Aged Care Services in Australia 2007-08: A Statistical Overview, AIHW cat. No. AGE 58 (Aged Care Statistics Series no. 22), AIHW, Canberra, 2008. ${ }^{4}$ M. O'Connor and A. Pearson, 'Ageing in Place-Dying in Place: Competing Discourses for Care of the Dying in Aged Care Policy', Australian Journal of Advanced Nursing, vol. 22, no. 2, 2004, pp. 32-8. 5 J. Wiles, 'Conceptualizing Place in the Care of Older People: The Contributions of Geographical Gerontology', Journal of Clinical Nursing, vol. 14, no. 8B, 2005 pp. 100-8.

${ }^{6}$ J. Gilmour, 'Hybrid Space: Constituting the Hospital as a Home Space for Patients', Nursing Inquiry, vol. 13, no. 1, 2006, pp. 16-22.

7 D. Sudnow, Passing On: The Social Organisation of Dying, Prentice-Hall, New Jersey, 1967.

8 B.G. Glaser and A.L. Strauss, Time for Dying, Aldine, Chicago,1968.

9 J. Lawton, The Dying Process, Routledge, London, 2000; H. Golander, 'Rituals of Temporality: The Social Construciton of Time in a Nursing Ward', Journal of Ageing Studies, vol. 9, no. 2, 1995, pp. 11935.

10 Lawton.
} 
11 Golander.

12 J.F. Gubrium, Living and Dying at Murray Manor, St Martin's Press, New York, 1975; J. Hockey, Experiences of Death: An Anthropological Account, Edinburgh University Press, Edinburgh, 1990; K. Froggatt, 'Life and Death in English Nursing Homes: Sequestration or Transition?', Ageing and Society, vol. 21, 2001, pp. 319-32.

13 Gubrium.

${ }^{14}$ Hockey.

15 Froggat.

16 O'Connor and Pearson.

17 O'Connor and Pearson.

18 B. Wadensten, 'The Content of Morning Time Conversations between Nursing Home Staff and Residents', International Journal of Older People Nursing, vol. 14, no. 8b, 2005, pp. 84-9.

19 J.F. Gubrium and J.A. Holstein, Institutional Selves: Troubled Identities in a Postmodern World, Oxford University Press, New York, 2001; J.A Holstein and J.F. Gubrium, The Self We Live By: Narrative Identity in a Postmodern World, Oxford University Press, New York, 2000.

20 Gubrium and Holstein, p. 10.

${ }^{21}$ Holstein and Gubrium.

22 C. Seale, 'Theories and Studying the Care of Dying People', British Medical Journal, vol. 317, 1998, pp. 1518-20.

${ }^{23}$ R. Harre, Personal Being, Harvard University Press, Boston, 1984.

24 J.F. Gubrium, 'Dying at Murry Manor', in J.B. Williamson and E.S. Shneidman (eds), Death: Current Perspectives, Mayfield Publishing Company, Mountain View, 1995.

25 A. Tuckett, 'Residents' Rights and Nurses' Ethics in the Australian Nursing Home', International Nursing Review, no. 52, 2005, pp. 219-24.

26 T. Karner and D. Bobbitt-Zeher, 'Losing Selves: Dementia Care as Disruption and Transformation', Symbolic Interaction, vol. 28, no. 4, 2006, pp. 549-70.

27 Sudnow, p. 74.

28 R.A. Kalish, Death, Grief and Caring Relationships, Brooks/Cole Publishing Company, Monterey, 1981. 